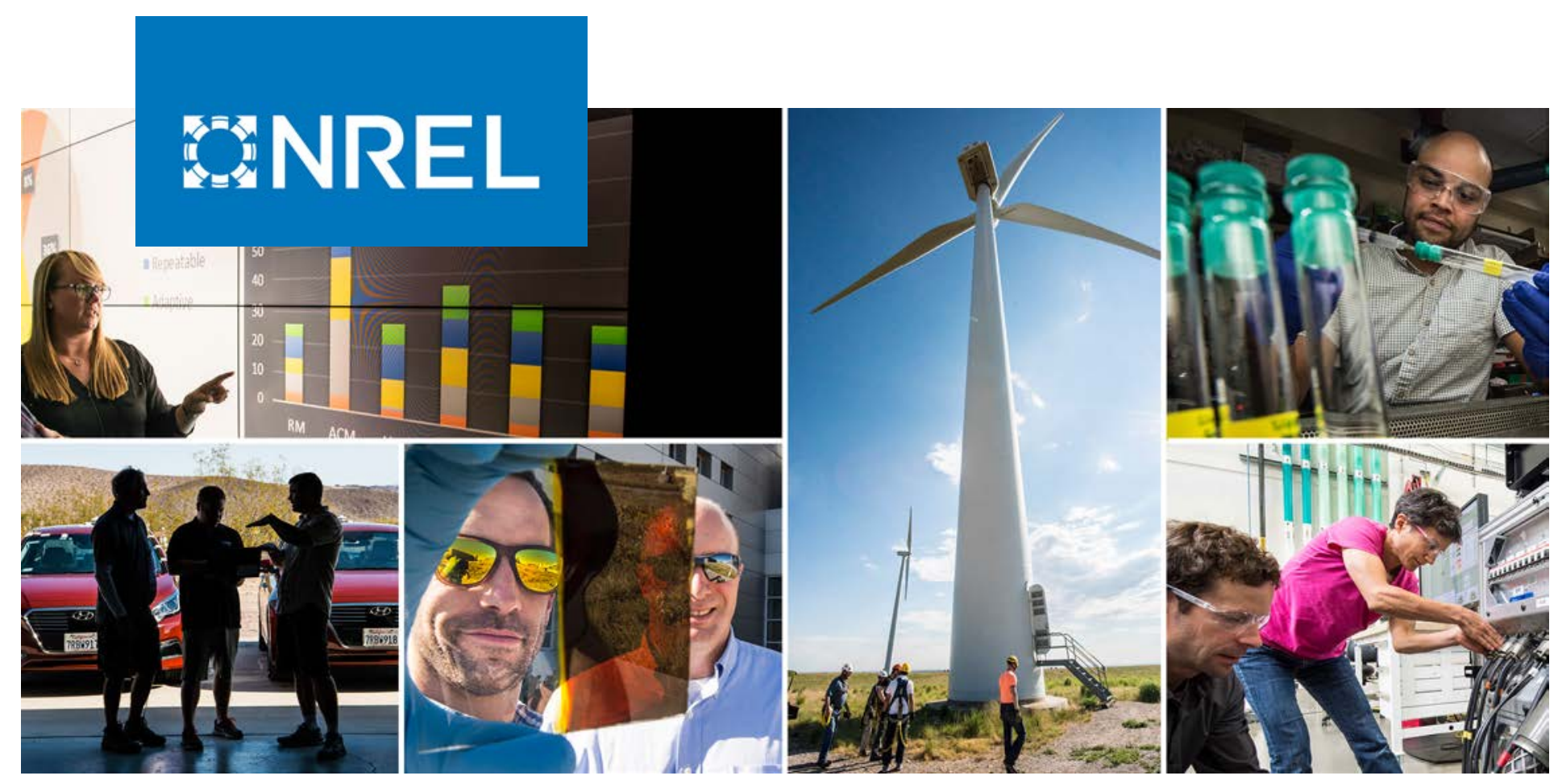

\title{
Highly Reliable Multi-Port Smart Inverter Modules for PV-Based Energy Systems
}

\section{Preprint}

Jinia Roy, Gabsu Seo, and Akanksha Singh

National Renewable Energy Laboratory

Presented at the 46th IEEE Photovoltaic Specialists Conference (PVSC 46)

Chicago, Illinois

June 16-21, 2019

NREL is a national laboratory of the U.S. Department of Energy

Office of Energy Efficiency \& Renewable Energy

Operated by the Alliance for Sustainable Energy, LLC

This report is available at no cost from the National Renewable Energy Laboratory (NREL) at www.nrel.gov/publications.

\section{Conference Paper}

NREL/CP-5D00-73857

July 2019 


\title{
GNREL
}

\section{Highly Reliable Multi-Port Smart} Inverter Modules for PV-Based Energy Systems

\section{Preprint}

\author{
Jinia Roy, Gabsu Seo, and Akanksha Singh
}

National Renewable Energy Laboratory

\author{
Suggested Citation \\ Roy, Jinia, Gabsu Seo, and Akanksha Singh 2019. Highly Reliable Multi-Port Smart \\ Inverter Modules for PV-Based Energy Systems: Preprint. Golden, CO: National \\ Renewable Energy Laboratory. NREL/CP-5D00-73857. \\ https://www.nrel.gov/docs/fy19osti/73857.pdf.
}

(C) 2019 IEEE. Personal use of this material is permitted. Permission from IEEE must be obtained for all other uses, in any current or future media, including reprinting/republishing this material for advertising or promotional purposes, creating new collective works, for resale or redistribution to servers or lists, or reuse of any copyrighted component of this work in other works.

NREL is a national laboratory of the U.S. Department of Energy Office of Energy Efficiency \& Renewable Energy Operated by the Alliance for Sustainable Energy, LLC

This report is available at no cost from the National Renewable Energy Laboratory (NREL) at www.nrel.gov/publications.

Contract No. DE-AC36-08GO28308
Conference Paper

NREL/CP-5D00-73857

July 2019

National Renewable Energy Laboratory 15013 Denver West Parkway Golden, CO 80401

303-275-3000 • www.nrel.gov 


\section{NOTICE}

This work was authored by the National Renewable Energy Laboratory, operated by Alliance for Sustainable Energy, LLC, for the U.S. Department of Energy (DOE) under Contract No. DE-AC36-08GO28308. Funding provided by U.S. Department of Energy Office of Energy Efficiency and Renewable Energy Solar Energy Technologies Office. The views expressed herein do not necessarily represent the views of the DOE or the U.S. Government. The U.S. Government retains and the publisher, by accepting the article for publication, acknowledges that the U.S. Government retains a nonexclusive, paid-up, irrevocable, worldwide license to publish or reproduce the published form of this work, or allow others to do so, for U.S. Government purposes.

This report is available at no cost from the National Renewable Energy Laboratory (NREL) at www.nrel.gov/publications.

U.S. Department of Energy (DOE) reports produced after 1991 and a growing number of pre-1991 documents are available free via www.OSTI.gov.

Cover Photos by Dennis Schroeder: (clockwise, left to right) NREL 51934, NREL 45897, NREL 42160, NREL 45891, NREL 48097, NREL 46526.

NREL prints on paper that contains recycled content. 


\title{
Highly Reliable Multi-Port Smart Inverter Modules for PV-Based Energy Systems
}

\author{
Jinia Roy, Gab-Su Seo, and Akanksha Singh \\ Power Systems Engineering Center, National Renewable Energy Laboratory \\ Golden, CO 80401, USA \\ E-mail: jinia.roy@nrel.gov; gabsu.seo@nrel.gov; akanksha.singh@nrel.gov
}

\begin{abstract}
Generally, large electrolytic capacitors (E-caps) are required to decouple the double-line frequency power fluctuation inherent in all single-phase dc-ac or ac-dc converters. These E-caps pose the weak link in the photovoltaic (PV) inverter because they have poor reliability as a result of short life expectancy and higher equivalent series resistance (ESR) which leads to lower system efficiency. In this paper, multiport smart dual-inverter modules are proposed for residential PV inverter systems with balanced outputs to eliminate the requirement of large decoupling capacitors, thus leading to more reliable and highly efficient inverter modules. The balanced dual outputs are controlled in phase quadrature such that the double frequency current is completely eliminated. One phase supports the standalone residential loads, and the other phase interfaces with the grid, which is synchronized to the utility grid. Also, the proposed modular configuration is scalable to accommodate higher power rating by stacking and paralleling multiple modules. Simulation results for the dual-inverter modules rated for $1 \mathrm{~kW}$ each are presented to validate the proposed concept. Experimental results from a controller hardware-in-the-loop (CHIL) platform also verify its feasibility.
\end{abstract}

Index Terms-Film capacitor, highly reliable, minimized decoupling capacitor, multiport residential PV inverter system, quadrature phase control, single phase dual-inverter modules.

\section{INTRODUCTION}

Solar photovoltaic (PV) is one of the largest growing renewable energy resources. The United States itself installed 1.7 GW of solar PV capacity in Q3 of 2018 to reach 60 GW of total installed capacity which is enough to power 11.3 million American homes [1]. Utility- and commercialscale PV systems are realized either as three-phase (central inverter) or single-phase (string inverter) versions depending on whether it is developed for the transmission or distribution levels, whereas the residential-scale PV is mostly single-phase to justify the system cost and efficiency for implementation. A limitation of the single-phase inverter system, however, is the presence of the large double-line frequency power ripple which requires a large electrolytic capacitor (E-cap), in general, to support the power fluctuation on the dc-side [2], [3], [4], [5].

Though E-caps have lower cost and a high capacitance-tovolume ratio, they have a higher equivalent series resistance (ESR) which impacts converter efficiency. More importantly, they have lower reliability making the complete PV inverter system prone to early failure [6], [7], [8]. A direct replacement of the E-caps with highly reliable film capacitors is cost prohibitive and affect converter power density as film capacitors have low capacitance-to-volume ratio. So active power decoupling schemes are proposed in literature to decrease the capacitance requirement, [9], [10], such that E-caps can be replaced by more reliable film capacitors without affecting converter power density. This is implemented by either adding an auxiliary power decoupling stage connected in parallel [11] or series [12], [13] to the main inverter, or allowing higher ripple on the main dc-link [14], [15], [16]. While the former approach increases the number of active and passive components, the later approach increases the converter loss and controller complexity. In general, though all of these implementations decrease the decoupling capacitance requirement, they increase the converter component count, controller complexity, cost, and/or loss.

In this paper, a multiport smart inverter module is proposed for single-phase PV inverter systems which is capable of eliminating the requirement of decoupling capacitor without active power decoupling scheme. This is realized by a dualinverter module, the outputs of which are controlled in phase quadrature with ideally balanced loads. This will ensure the double-line frequency power to be completely eliminated, thus no decoupling capacitor will be required ideally. One of the phases is made to support the stand-alone residential loads and the other phase interfaces to the grid, which is synchronized to the utility grid. Also the proposed modular configuration is scalable to accommodate higher power rating by stacking and paralleling multiple modules. In the presence of any unbalance due to system non-idealities, however, a very small decoupling capacitor will be used, which can be configured with only film capacitors. Consequently the E-caps are completely eliminated thus enhancing the reliability and improving the efficiency of the complete conversion system.

The rest of the paper is organized as follows. Section II gives a brief overview of the proposed system. Section III presents the operating principles and design consideration and guideline for selecting the passive component values. Section IV shows the simulation results obtained from the PLECS simulation platform and gives the details of the preliminary controller hardware-in-the-loop (CHIL) based experimental setup with OPAL-RT and Texas Instruments 320F28379D based controller board, developed to validate the proposed 


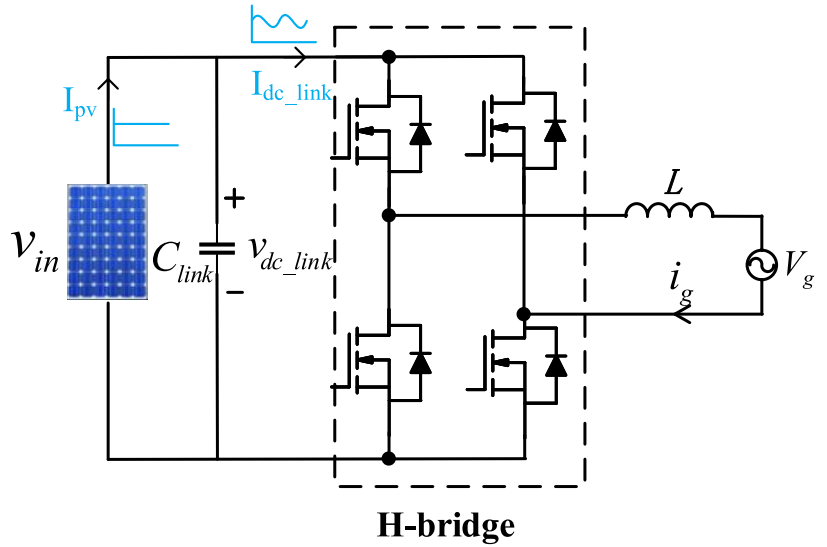

Fig. 1. Single-phase full bridge inverter (H4) for the PV application showing the input capacitor $C_{i n}$ for double-line frequency power decoupling.

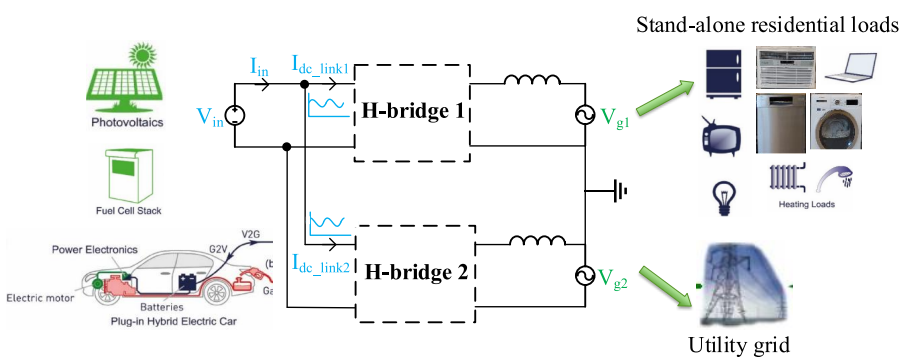

Fig. 2. Proposed multiport dual-inverter module structure capable of eliminating the capacitor for double-line frequency power decoupling with $v_{g 1}$ controlled to be in quadrature of $v_{g 2}$.

system configuration. Finally Section V concludes the paper.

\section{SYSTEM CONFIGURATION}

The presence of the fluctuation in the dc-link voltage and current of a conventional single-phase PV inverter can be appreciated from the following system analysis (1)-(2), where $v_{g}$ is the grid voltage, $i_{g}$ is the grid current, and $P_{g}$ is the grid output power. The grid power $P_{g}$ has an ac component superimposed on the dc power component which oscillates at a frequency of $2 \omega_{\text {grid }}$ as illustrated in (2) where $\omega_{\text {grid }} / 2 \pi$ is the grid line frequency.

$$
\begin{gathered}
v_{g}=V_{g} \sin \left(\omega_{\text {grid }} t\right) ; \quad i_{g}=I_{g} \sin \left(\omega_{\text {grid }} t\right) \\
P_{g}=\frac{V_{g} I_{g}}{2}\left(1-\cos 2 \omega_{\text {grid }} t\right)
\end{gathered}
$$

Fig. 1 shows the conventional single-phase PV inverter system illustrating the presence of a large double-line frequency ripple on the dc-link current to support the ripple power. Thus a large decoupling capacitor $C_{l i n k}$ is required to ensure that the ripple is absorbed in the energy storing capacitor and does not impact the PV output current, which will otherwise impact the maximum power point tracking (MPPT) efficiency of the inverter system. It has been shown in [17] that with $8.5 \%$ ripple in input voltage, the MPPT efficiency degrades to $98 \%$.
The required value of this $C_{\text {link }}$ to support the ripple power is inversely proportional to the dc-link average $V_{a v g}$ and peakto-peak ripple voltage $V_{r}$ while it is directly proportional to the dc power fed to the grid $\frac{V_{g} I_{g}}{2}$ as shown below in (3).

$$
C_{\text {link }}=\frac{V_{g} I_{g}}{4 \omega_{\text {grid }} V_{\text {avg }} V_{r}}=\frac{S_{g}}{2 \omega_{\text {grid }} V_{\text {avg }} V_{r}}
$$

To mitigate this problem, a multiport dual-inverter module is proposed for the residential system as illustrated in Fig. 2. The input to the module can be obtained from the PV module or any other renewable energy resources like fuel cell. It can also be connected to electric vehicle in vehicle-to-grid (V2G) mode. The output side of the system consists of dualinverter, each with single-phase ac voltage which is controlled to be in phase quadrature. Considering unity power factor (UPF) operation, (4) and (5), respectively give the voltage and current of each of the output of the dual-inverter module.

$$
\begin{gathered}
v_{g 1}=V_{g 1} \sin \left(\omega_{\text {grid }} t-\pi / 2\right) \\
i_{g 1}=I_{g 1} \sin \left(\omega_{\text {grid }} t-\pi / 2\right) \\
v_{g 2}=V_{g 2} \sin \left(\omega_{\text {grid }} t\right) \\
i_{g 2}=I_{g 2} \sin \left(\omega_{\text {grid }} t\right)
\end{gathered}
$$

One of the output phases is envisioned to support the residential loads which can be $120 \mathrm{~V}$ or $230 \mathrm{~V}$, while the other phase will feed the balance power to the power grid. In rural areas where the utility grid is not available, both the phases can be configured to supply two separate combination of stand-alone loads. In both of the above scenarios, controlling the ac-output voltages in phase quadrature will not impact the operational behaviour of the stand-alone loads. If $V_{g 1}=V_{g 2}=V_{g}$ and ensuring balanced load in both the phases $I_{g 1}=I_{g 2}=I_{g}$, then the following condition (6) is obtained which shows the complete elimination of the power ripple in the presence of balanced loads on both the phases, thus confirming the elimination of the decoupling capacitor requirement.

$$
\begin{aligned}
P_{g 1}+P_{g 2} & =\frac{V_{g 1} I_{g 1}}{2}\left(1+\cos 2 \omega_{\text {grid }} t\right) \\
+ & \frac{V_{g 2} I_{g 2}}{2}\left(1-\cos 2 \omega_{\text {grid }} t\right)=V_{g} I_{g}
\end{aligned}
$$

To make the system self-sustaining, energy storage devices like battery unit or electric flywheel can be connected in the input port of the system through a bidirectional buckboost dc-dc converter. Also to support a wide range of PV input voltage to address the partial shading condition, an input dc-dc boost stage can be cascaded after the PV input. The front-end boost converter can also implement the MPPT for the PV module. Further, in the presence of non-unity 


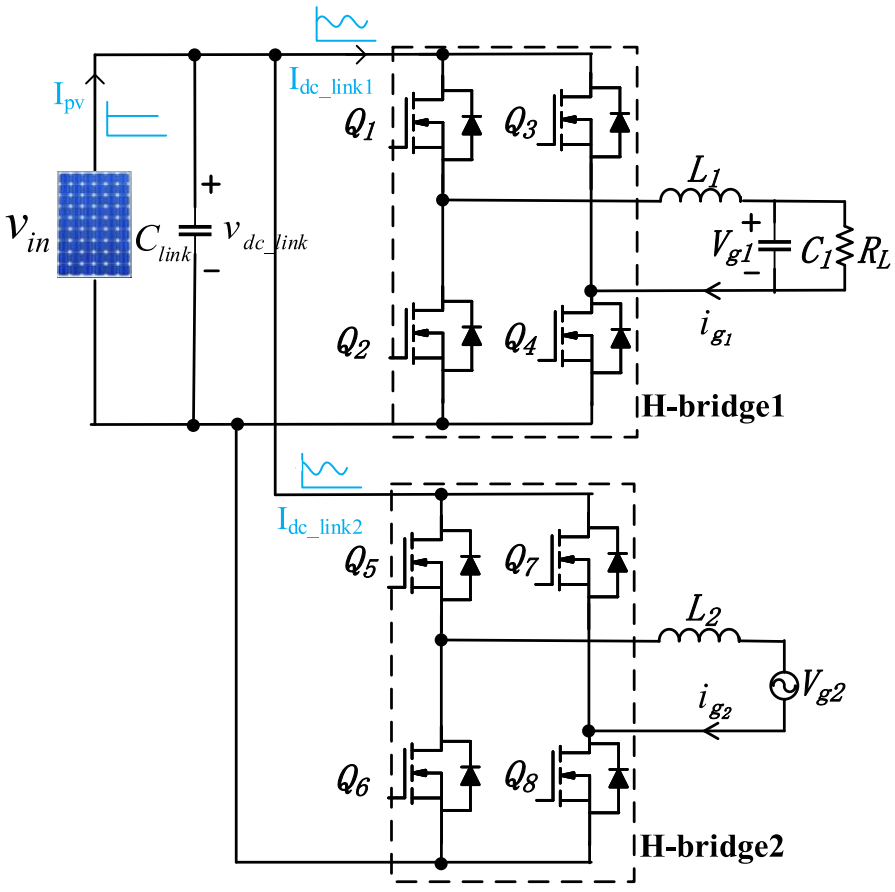

Fig. 3. Circuit schematic of the proposed multiport dual-inverter.

power factor (UPF) operation or phase imbalance of this dual-inverter module (phase imbalance during faults is also a concern for three-phase system [18] which otherwise require smaller capacitance for power decoupling), a small capacitor can be used at the dc-link to support the unbalanced power decoupling in conjunction with the energy storage device. Additional sophisticated control for the dual-inverters can also be implemented as in [18] in case of phase imbalance to reduce the oscillating power (this is part of our future work). The capacitor value can thus be small and realized by a film capacitor which does not have any reliability bottleneck nor a high ESR unlike E-caps.

\section{DESIGN CONSIDERATION}

Fig. 3 shows an example of the proposed system configuration. Each of the phases has four switches $Q_{1}-Q_{4}$ and $Q_{5}-Q_{8}$ respectively. $Q_{2}, Q_{4}, Q_{6}$, and $Q_{8}$ are complementary to $Q_{1}, Q_{3}, Q_{5}$, and $Q_{7}$ respectively, similar to conventional H-bridge inverter. The output filter can be either implemented by a single inductor $L$ or an $L C L$ combination. Here only $L$ filter is considered for simplicity. For standalone loads $L C$ filter will be used as shown. As mentioned before, a small capacitor $C_{\text {link }}$ is added at the input dc-link to support partial ripple power during phase imbalance or non-UPF operation. The other consideration for design of $C_{\text {link }}$ include the minimization of the switching frequency ripple on the PV input.

Any of the conventional PWM modulation schemes including bipolar, unipolar, or hybrid modulation can be used. Even though the unipolar modulation scheme increases the effective switching frequency and reduces the output filter

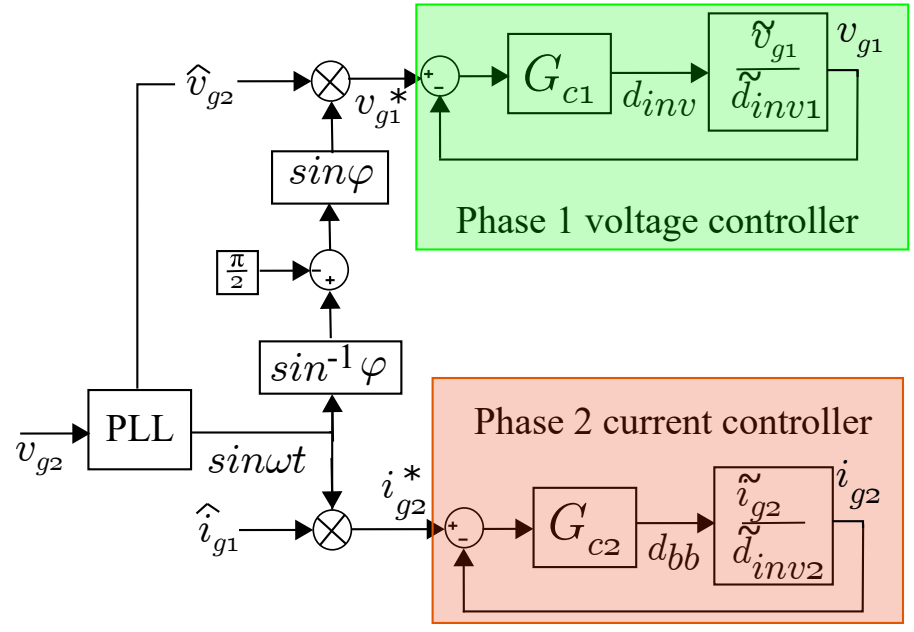

Fig. 4. Controller block diagram of the proposed multiport dual-inverter module.

size, however, this has potential ground current problem for PV application. Parasitic capacitance $C_{P V}$ of the order of $\mathrm{nF}$ is formed between the PV terminals and ground (and therefore grid neutral). The typical value of $C_{P V}$ is $60-110$ $\mathrm{nF} / \mathrm{kW}$ in standard PV modules and $100-160 \mathrm{nF} / \mathrm{kW}$ in thinfilm PV modules [19]. As a high-frequency (typically switching frequency and their harmonics) voltage is introduced in between the PV negative terminal relative to the grid neutral by unipolar modulation, this technique would generate highfrequency capacitive coupled common-mode ground current which increases the system loss, distort the grid current, and induce severe electromagnetic interference (EMI). On the contrary, with bipolar and hybrid modulation techniques and with similar inductance in the differential path, the ground current is ideally eliminated, so these modulation schemes are preferred for PV applications.

\section{VALIDATION AND DISCUSSION}

\section{A. Model and controller details}

The proposed system configuration is validated in the PLECS simulation platform for a $2-\mathrm{kW}$ system, $1 \mathrm{~kW}$ for each of the H-bridge inverters. The PV module is closely emulated in simulation by a $450-\mathrm{V}$ dc source in series with a $10 \Omega$ resistor [20]. The values of the passive components and switching frequency are given in Table I. A capacitor of $5 \mu F$ is used in the dc-link to support any small ripple power that might be introduced from components non-idealities and

TABLE I

Circuit COMPONENT DETAILS FOR SIMULATION AND HIL EXPERIMENT

\begin{tabular}{|c|c|}
\hline Component & Parameters \\
\hline$C_{\text {link }}$ & $5 \mu \mathrm{F}$ \\
\hline$L_{1}, L_{2}$ & $2 \mathrm{mH}$ \\
\hline$C_{1}$ & $2 \mu \mathrm{F} / 230 \mathrm{~V} \mathrm{AC}$ \\
\hline Switching frequency $f_{s w}$ & $100 \mathrm{kHz}$ (PLECS), $16 \mathrm{kHz}$ (CHIL) \\
\hline
\end{tabular}


switching frequency of power electronics. Note that $520 \mu \mathrm{F}$ -100 times more- will be needed in single-phase inverter for $10 \%$ voltage ripple for same rated power. Conventionally, by allowing safety limit, capacitor in the range of $\mathrm{mFs}$ are used in state-of-the-arts inverters.

Voltage is controlled for phase 1 connected to the standalone loads while current is controlled for phase 2 which is connected to the grid as shown in Fig. 4. The phase and frequency of the sinusoidal waveform is determined by a phase-locked loop (PLL) based on phase 2 voltage $v_{g 2}$. Phase 1 voltage reference $v_{g 1}^{*}$ is derived based on the grid voltage $v_{g 2}$ magnitude, frequency, and phase (magnitude and frequency is kept identical while the phase is offset by $\pi / 2$ ). On the contrary, phase 2 current reference $i_{g 2}^{*}$ is derived based on phase 1 load current $i_{g 1}$ (peak of both are made equal to make both the phases balanced) while the phase being same as the $v_{g 2}$ for UPF operation. Both the voltage and current
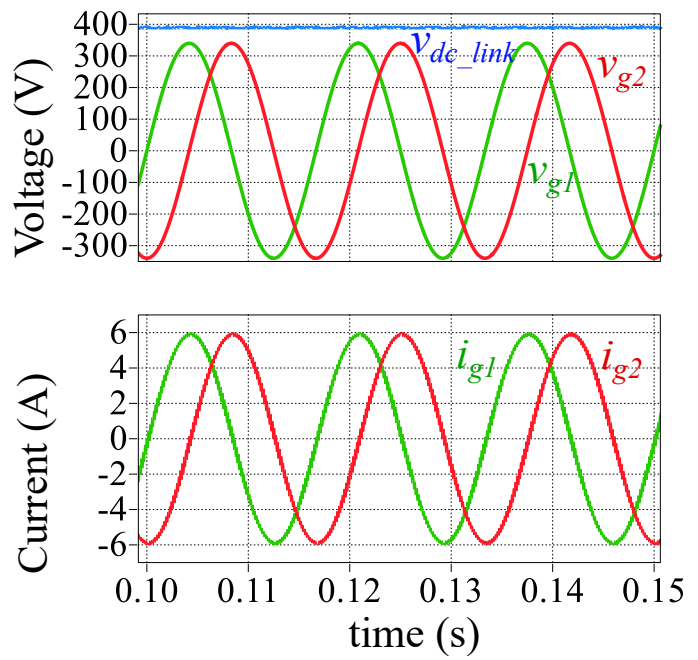

(a)

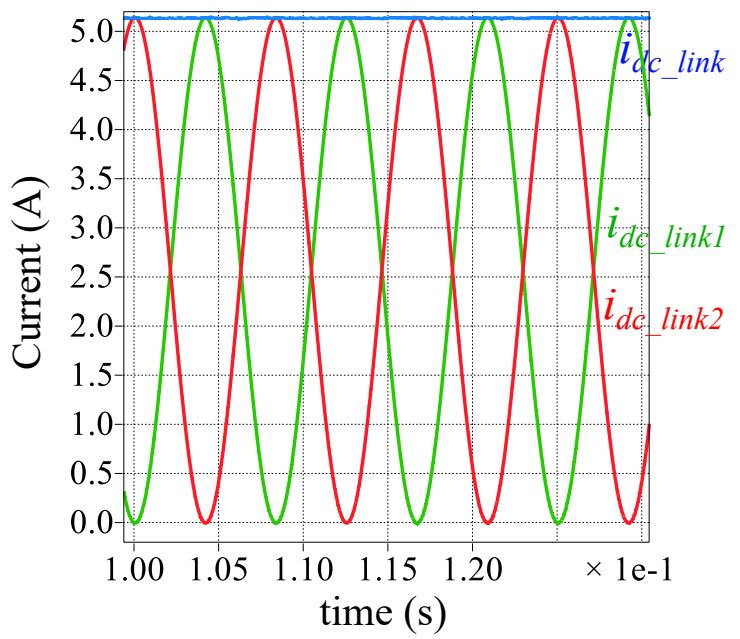

(b)

Fig. 5. Simulation results for a $2 \mathrm{~kW}, 240 \mathrm{~V}$ ac output for a dual-inverter prototype at UPF condition from the PLCES simulation platform: (a) output voltages and currents and dc-link voltage, (b) cycle-by-cycle average of the dc-link and input currents.

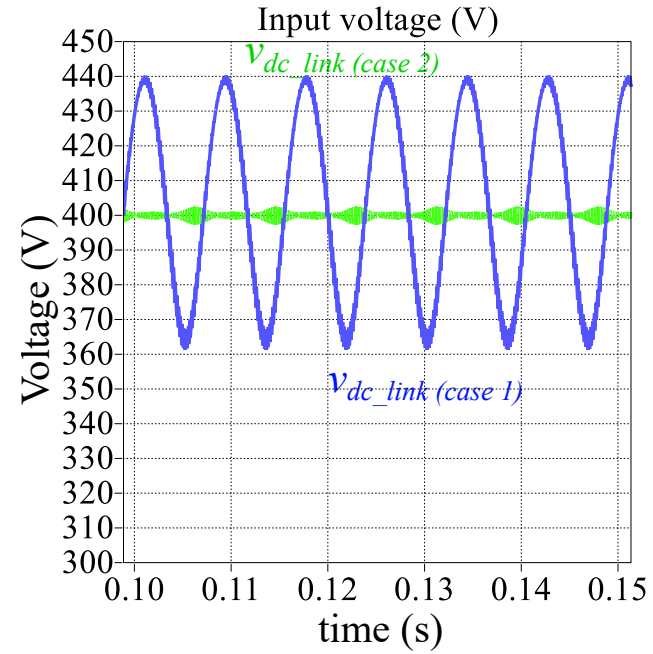

Fig. 6. PLECS simulation results showing the comparison of the dclink voltage ripple with the conventional (case 1) and proposed (case 2) approaches.

controllers $\left(G_{c 1}\right.$ and $G_{c 2}$ respectively) are implemented by basic PI controller. More sophisticated and advanced control for better dynamic response is part of our future study. $d_{i n v 1}$ and $d_{i n v 2}$ as shown in Fig. 4 are the duty cycles for phase 1 and phase 2 respectively. Bipolar modulation scheme with appropriate dead time for the complementary switch pairs is used to generate all of the eight gate signals.

\section{B. Simulation Results}

Figs. 5 and 6 give the simulation results from the PLECS platform. Fig. 5a shows the dc-link voltage and output voltages and currents for both the phases at UPF condition while Fig. 5b illustrates the cycle-by-cycle average of the dc-link and input currents to eliminate the switching frequency components for the ease of analysis and performance comparison of the double-line frequency ripple. It can be seen that $v_{g 1}$ and $v_{g 2}$ are in phase quadrature with $i_{g 1}$ and $i_{g 2}$ in phase with $v_{g 1}$ and $v_{g 2}$ respectively. The dc-link has no doubleline frequency ripple, even without using any decoupling capacitor, as analyzed before. This is also corroborated by Fig. 5b, though the averaged dc-link currents have double-line frequency power ripple superimposed on the dc component, the total averaged input current which is a sum of the two averaged dc-link currents is very close to dc with negligible low frequency oscillation with balanced two-phase loads.

Fig. 6 presents the comparison of the dc-link voltages with the conventional (case 1) and proposed (case 2) approaches. Case 1 is simulated for the $2 \mathrm{~kW}$ system where the voltage and current of both the inverters are in phase, while for case 2 they are in phase quadrature. It can be observed that with a 5 $\mu F$ input capacitor the voltage swing in a single phase inverter is substantial which will affect the MPPT efficiency. While with the proposed dual-inverter configuration the doubleline frequency ripple is completely eliminated and only the switching frequency ripple is present. 


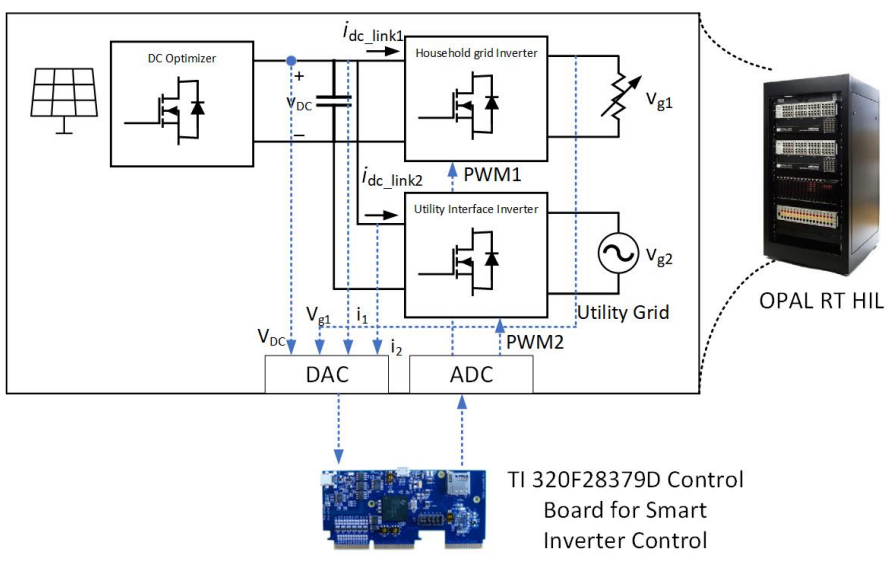

Fig. 7. Experiment setup for validation using a CHIL system. Controller of the multiport smart inverter modules is implemented in a Texas Instruments 320F28379D based controller board while the others including inverter hardware, PV modules, and loads are emulated in the OPAL-RT.

\section{Hardware Verification}

In order to validate the proposed system, an experimental testbed is constructed using a CHIL system as shown in Fig. 7. The front-end dc-dc converter is not currently modeled, however this can be added for implementing the MPPT of the input PV supply. The hardware of the proposed configuration is modeled in the OPAL-RT OP5600 based real-time simulation platform, while the control is implemented with Texas Instruments 320F28379D based controller board. A Virtex-7 FPGA expansion module OP5607 is used to expand on the basic OP5600 module to implement a smaller sampling time through eFPGAsim. Communications between the OPAL-RT and the DSP controller is realized by signal communication cables.

The CHIL-based open loop experiment results are presented in Fig. 8. A switching frequency of $16 \mathrm{kHz}$ is used for all the eight switches. It can be seen that significant double-line frequency ripple is present on the dc-link voltage and current for case 1 (Fig. 8a), when both the inverters operate in phase as is conventionally done. However, in case 2 (Fig. 8b) with the proposed approach the ripple on the dclink is eliminated for the balanced operation, thus the MPPT efficiency will not be compromised even with the use of very small capacitor. The result verifies the complete removal of the double-line frequency voltage and current ripple from the dc-link for the balanced loads in both the phases of the proposed control approach.

\section{CONCLUSION}

This paper proposes multiport, smart dual-inverter modules for DER based energy systems. By controlling the dual output in quadrature and balanced, the double frequency current and thus the E-caps can be completely eliminated, eventually increasing the reliability of the system. One of the phases is envisioned to support the stand-alone residential loads and the other phase supports the utility grid or another set of

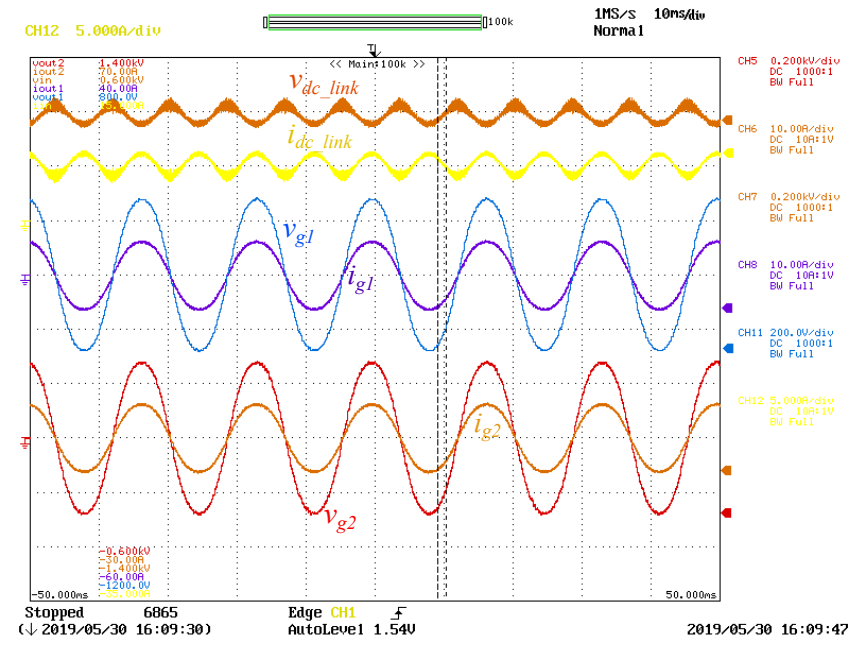

(a)

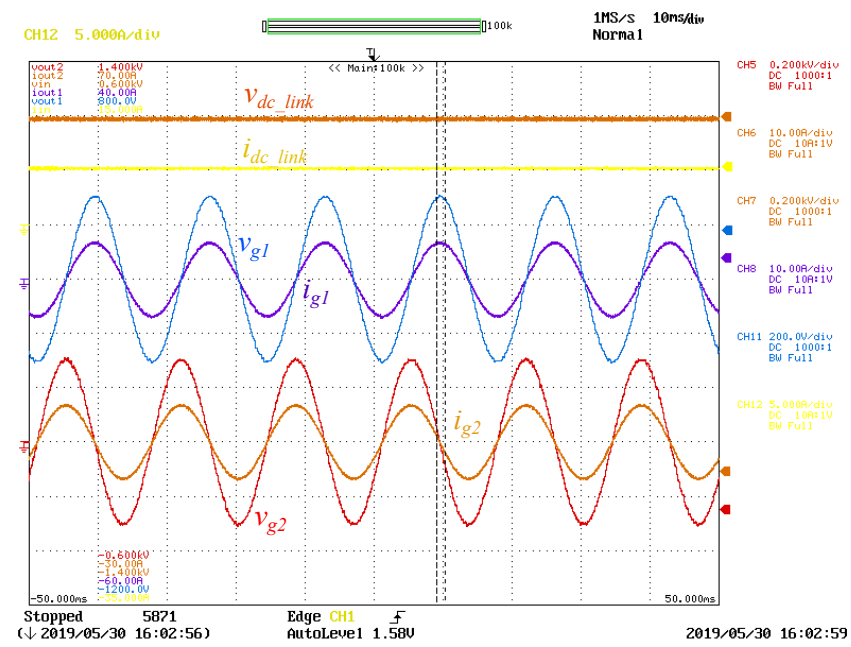

(b)

Fig. 8. CHIL based experimental results for the proposed dual-inverter system operating in phase quadrature at $2 \mathrm{~kW}$ UPF (voltage: $200 \mathrm{~V} /$ div, $i_{g 1}, i_{g 2}: 10 \mathrm{~A} / \mathrm{div}, i_{d c_{-} l i n k}: 5 \mathrm{~A} / \mathrm{div}$, time $\left.: 10 \mu \mathrm{s} / \mathrm{div}\right)$ showing dc-link and output voltages and currents for (a) conventional approach (case 1), (b) proposed approach (case 2).

stand-alone loads. Also the proposed modular configuration is scalable to accommodate an increased power rating by stacking and paralleling multiple modules. Simulation results validate the concept of complete removal of the double-line frequency voltage and current ripple for the balanced loads in both the phases of the proposed inverter modules. CHILbased experimental results are also presented to validate the proposed concept.

\section{ACKNOWLEDGMENT}

This work was authored by the National Renewable Energy Laboratory, operated by Alliance for Sustainable Energy, LLC, for the U.S. Department of Energy (DOE) under Contract No. DE-AC36-08GO28308. The funding is provided by the DOE Office of Energy Efficiency and Renewable Energy Solar Energy Technologies Office. The views expressed in the 
article do not necessarily represent the views of the DOE or the U.S. Government. The U.S. Government retains and the publisher, by accepting the article for publication, acknowledges that the U.S. Government retains a nonexclusive, paidup, irrevocable, worldwide license to publish or reproduce the published form of this work, or allow others to do so, for U.S. Government purposes.

The authors would also like to extend thanks to Ismael Mendoza and Soumya Tiwari for their help with the OPALRT based experimental setup.

\section{REFERENCES}

[1] "U.S. Solar Market Insight: Q3 2018 Report, Solar Energy Industry Association (SEIA)," https://www.seia.org/us-solar-market-insight, Jan. 2019, [Online].

[2] Y. Sun, Y. Liu, M. Su, W. Xiong, and J. Yang, "Review of active power decoupling topologies in single-phase systems," IEEE Transactions on Power Electronics, vol. 31, no. 7, pp. 4778-4794, July 2016.

[3] J. Roy, Y. Xia, and R. Ayyanar, "High step-up transformerless inverter for ac module applications with active power decoupling," IEEE Transactions on Industrial Electronics, vol. 66, no. 5, pp. 3891-3901, May 2019.

[4] Y. W. Cho, W. J. Cha, J. M. Kwon, and B. H. Kwon, "Improved single-phase transformerless inverter with high power density and high efficiency for grid-connected photovoltaic systems," IET Renewable Power Generation, vol. 10, no. 2, pp. 166-174, 2016.

[5] J. Roy, Y. Xia, and R. Ayyanar, "Half-bridge voltage swing inverter with active power decoupling for single phase pv systems supporting wide power factor range," IEEE Transactions on Power Electronics, pp. 1-1, 2018

[6] J. Flicker, R. Kaplar, M. Marinella, and J. Granata, "Pv inverter performance and reliability: What is the role of the bus capacitor?" in Photovoltaic Specialists Conference (PVSC), Volume 2, 2012 IEEE 38th. IEEE, 2012, pp. 1-3.

[7] H. Zhang, X. Li, B. Ge, and R. S. Balog, "Capacitance, dc voltage utilizaton, and current stress: Comparison of double-line frequency ripple power decoupling for single-phase systems," IEEE Industrial Electronics Magazine, vol. 11, no. 3, pp. 37-49, Sept 2017.

[8] A. Sastry, S. Kulasekaran, J. Flicker, R. Ayyanar, G. TamizhMani, J. Roy, D. Srinivasan, and I. Tilford, "Failure modes and effect analysis of module level power electronics," in 2015 IEEE 42nd Photovoltaic Specialist Conference (PVSC), June 2015, pp. 1-3.

[9] R. Chen, Y. Liu, and F. Z. Peng, "DC capacitor-less inverter for singlephase power conversion with minimum voltage and current stress," IEEE Transactions on Power Electronics, vol. 30, no. 10, pp. 54995507, Oct 2015

[10] Y. Xia, J. Roy, and R. Ayyanar, "A high performance T-type singlephase doubly grounded transformer-less photovoltaic inverter with active power decoupling," in 2016 IEEE Energy Conversion Congress and Exposition (ECCE), Sept 2016.

[11] P. T. Krein, R. S. Balog, and M. Mirjafari, "Minimum energy and capacitance requirements for single-phase inverters and rectifiers using a ripple port," IEEE Transactions on Power Electronics, vol. 27, no. 11, pp. 4690-4698, Nov 2012.

[12] R. Wang, F. Wang, D. Boroyevich, R. Burgos, R. Lai, P. Ning, and K. Rajashekara, "A high power density single-phase PWM rectifier with active ripple energy storage," IEEE Transactions on Power Electronics, vol. 26, no. 5, pp. 1430-1443, May 2011.

[13] W. Liu, K. Wang, H. S. h. Chung, and S. T. h. Chuang, "Modeling and design of series voltage compensator for reduction of dc-link capacitance in grid-tie solar inverter," IEEE Transactions on Power Electronics, vol. 30, no. 5, pp. 2534-2548, May 2015.

[14] Y. Xia, J. Roy, and R. Ayyanar, "A capacitance-minimized, doubly grounded transformer less photovoltaic inverter with inherent activepower decoupling," IEEE Transactions on Power Electronics, vol. 32, no. 7, pp. 5188-5201, July 2017.

[15] D. G. Lamar, J. Sebastian, M. Arias, and A. Fernandez, "On the limit of the output capacitor reduction in power-factor correctors by distorting the line input current," IEEE Transactions on Power Electronics, vol. 27, no. 3, pp. 1168-1176, March 2012.
[16] J. Roy, Y. Xia, and R. Ayyanar, "Performance evaluation of singlephase transfomer-less pv inverter topologies," in 2018 IEEE Applied Power Electronics Conference and Exposition (APEC), March 2018, pp. 3250-3255.

[17] S. B. Kjaer, J. K. Pedersen, and F. Blaabjerg, "A review of single-phase grid-connected inverters for photovoltaic modules," IEEE Transaction on Industry Applications, vol. 41, no. 5, pp. 1292-1306, Sep. 2005.

[18] J. Zhou, F. Tang, Z. Xin, S. Huang, P. C. Loh, and J. Jiang, "Differences between continuous single-phase and online three-phase powerdecoupled converters," IEEE Transactions on Power Electronics, pp. $1-1,2018$.

[19] "Capacitive leakage currents," Aug, SMA technical information, Ableitstrom-TI-en-25, version 2.5.

[20] W. Liang, Y. Liu, B. Ge, H. Abu-Rub, R. S. Balog, and Y. Xue, "Double-line-frequency ripple model, analysis, and impedance design for energy-stored single-phase quasi-z-source photovoltaic system," IEEE Transactions on Industrial Electronics, vol. 65 , no. 4, pp. 3198 3209, April 2018. 